\title{
Comparative Effect of Selected Anti-mildew Agents on Bamboo Bundles
}

\author{
Zhenzeng Wu, ${ }^{\mathrm{a}, *}$ John Tosin Aladejana, ${ }^{\mathrm{b}}$ Daobang Huang, ${ }^{\mathrm{b}}$ Xinhuai Gong, \\ Shuqiong Liu, ${ }^{a}$ Xiaodong (Alice) Wang, ${ }^{\mathrm{c}}$ and Yongqun Xie ${ }^{\mathrm{b}, *}$
}

\begin{abstract}
Nutrient-rich raw bamboo materials can be infected by mildew when exposed to water or high humid environments. This not only affects the appearance of bamboo products, but it also contributes to respiratory diseases. Herein, four anti-mildew agents, i.e., boric acid, copper sulphate, alumina phosphate sol, and alumina silicate sol, were used to evaluate their anti-mildew performances. The results showed that the adequate anti-mold concentrations of boron and copper were $2 \%$ and $0.7 \%$, respectively. The optimum mass ratio of aluminum phosphate sol and silicone aluminum sol were 1 to 1 (2\% phosphoric acid addition) and 10 to 1 (aluminum salt addition was $1.5 \%$ ). There were significant differences in the prevention and treatment effects of different mold inhibitors on mold and discoloration bacteria. The efficacies order of the anti-mildew property was as follows: copper sulphate > alumina silicate sol > boric acid > alumina phosphate sol. In addition, the order for stain fungi resistance was: boric acid > alumina phosphate sol > alumina silicate sol > copper sulphate. The selected anti-mildew agents showed promising application requirements as an active ingredient in bamboo preservative systems.
\end{abstract}

DOI: 10.15376/biores.17.1.243-254

Keywords: Bamboo bundles; Anti-mildew; Stain fungal resistant; Inorganic agent

Contact information: a: The College of Ecology and Resource Engineering, Wuyi University, No. 16, Wuyi Avenue, Wuyishan City, Fujian 354300 P.R. China; b: The College of Material Engineering, Fujian Agriculture and Forestry University, 15 Shangxiadian Road, Fuzhou, Fujian 350002 P.R. China; c: Department of Wood and Forest Sciences, Laval University, Quebec G1 V 0A6 Canada;

*Corresponding authors: zhenzeng.wu@outlook.com; fafuxieyq@aliyun.com

\section{INTRODUCTION}

China is known as the "kingdom of bamboo", with 39 bamboo categories and more than 500 species (Li and Feng 2019; Lian and Wu 2021). Being one of the most promising biomass resources, bamboo has been generating research attention due to its excellent mechanical strength and fast growth (Singh et al. 2020; Chen et al. 2021). It is one of the ideal substitutes for wood. It has natural advantages, e.g., a short time to form, easy to shape, and outstanding environmental protection value (Zhang et al. 2021; Zhu et al. 2021). However, bamboo has high starch, protein, carbohydrate, and fat contents, which objectively provides nutrients for mold growth and reproduction, leading to easy mildew formation on bamboo during the processing stage, transportation, and use (Li et al. 2017b; Wu et al. 2019).

To overcome this challenge and enhance the productive value of bamboo products, numerous procedures have been explored. Physical methods, i.e., high-temperature processes (Cheng et al. 2013), microwave (Cheng and Ye 1999; Kang et al. 2009) and $\gamma$ - 
rays (Sun et al. 2011), and chemical treatments are primary methods for protecting bamboo from mildew (Cheng et al. 2013). Anti-mildew agents can be divided into organic and inorganic agents. Some organic agents, i.e., pentachlorophenol, 1,2-dibromoethane, and IPBC, display some disadvantages, e.g., short efficacy, not resistant to high temperatures, and cause environmental pollution (Cull et al. 1983; Kitchin and Brown 1986; Kjellow et al. 2010; Zhang et al. 2020). Inorganic agents are primarily formulated by copper (Guo et al. 2005; Sun et al. 2012; Mercer and Frostick 2014), silver (Jalali et al. 2016; Ju et al. 2021), zinc (Zhang et al. 2013; Petkova et al. 2014; Okyay et al. 2015; Li et al. 2017b), and other antibacterial materials (Chen et al. 2009; Filpo et al. 2013; Li et al. 2017a), e.g., ceramics, zeolite, and silicone. Such inorganic agents have the advantages of high efficiency and low toxicity, as well as being broad-spectrum, heat resistant, and easily processed. Stirling et al. (2008) selected micronized copper salt to treat southern pine and found that copper particles can enter the cell wall, cell cavity, wood-ray, and edge of the hole, but most of the particulate copper was present in the large gaps. Copper and boron are two common bamboo anti-mold agents, which have a wide source, are easy to use, and are broad spectrum with a high efficiency and cost-efficiency, which could be applied to recombinant bamboo during production and preparation.

The sol-gel method is a technique that is feasible, with facile fabrication processes (Saka et al. 2001). It has been explored for usage to prepare inorganic-organic composite materials, making modifiers more evenly distributed in the material and forming an inorganic protective film. It improves the dimensional stability of the material, as well as the physical mechanics and other properties. Pries and Mai (2013) prepared a cationcontaining silicone sol to treat wood; they found that the wood preservation was considerably improved. In addition, silicone sol and aluminum phosphate gels can be used as antibacterial coatings (Lam et al. 2021). Thus, it is of great importance to solve the problem of bamboo mold via the sol-gel method. To date, there is no systematic comparison of the anti-mildew and stain fungal resistant performance among boric, copper, aluminum silicon sol (Al-Si), and aluminum phosphate sol (Al-P) agents.

In this study, different concentrations of copper and boron anti-mold agents and different mass ratios of $\mathrm{Al}-\mathrm{Si}$ and $\mathrm{Al}-\mathrm{P}$ were used to treat bamboo bundles. The average mildew control effectiveness of three strains of mildew (Aspergillus niger V. Tiegh, Penicillium citrinum Thom, and Trichoderma viride Pers. ex Fr.) and one type of stain fungi (Botryodiplodia theobromae Pat.) (AMCE) were used as the index to evaluate the anti-mildew and stain fungi resistant effect. In addition, the optimal concentration or mass ratio of the anti-mildew agent was analyzed and presented.

\section{EXPERIMENTAL}

\section{Materials}

Bamboo bundles (BB), (Phyllostachys heterocycla), with a moisture content of approximately 9\%, were received from Zhejiang Dasso Group Co., Ltd. (Hangzhou, China). Three mildews, i.e., Aspergillus niger V. Tiegh (AVT), Penicillium citrinum Thom (PCT), and Trichoderma viride Pers. ex Fr. (TPF) and one stain fungus, Botryodiplodia theobromae Pat. (BTP), were bought from Beijing Zhongkezhijian Biotechnology Co. LTD (Beijing, China). The sodium silicate $\left(\mathrm{Na}_{2} \mathrm{SiO}_{3}\right)$, aluminum sulfate $\left[\mathrm{Al}_{2}\left(\mathrm{SO}_{4}\right)_{3}\right]$, sulfuric acid $\left(\mathrm{H}_{2} \mathrm{SO}_{4}\right)$, copper sulfate $\left(\mathrm{CuSO}_{4}\right)$, phosphoric acid $\left(\mathrm{H}_{3} \mathrm{PO}_{4}\right)$, and boric acid $\left(\mathrm{H}_{3} \mathrm{BO}_{4}\right)$ were bought from Tianjin Zhiyuan Chemical Reagent Co., Ltd. (Tianjin, China), 
and were pure analytical grade.

\section{Methods}

Preparation of anti-mildew agents and anti-mildew process of bamboo bundles (BB)

For the boric anti-mildew (B) agent: $14.2 \mathrm{~g}, 24.4 \mathrm{~g}, 42.6 \mathrm{~g}, 56.8 \mathrm{~g}$, and $71 \mathrm{~g}$ of $\mathrm{H}_{3} \mathrm{BO}_{4}$ was added into $680 \mathrm{~mL}$ of water at a temperature of $90{ }^{\circ} \mathrm{C}$ to make a $2 \%, 4 \%, 6 \%$, $8 \%$, and $10 \%$ boric density gradient, respectively. For the copper anti-mildew $(\mathrm{Cu})$ agent: $4.83 \mathrm{~g}, 9.66 \mathrm{~g}, 14.49 \mathrm{~g}, 19.31 \mathrm{~g}$, and $24.14 \mathrm{~g}$ of $\mathrm{CuSO}_{4}$ was added into $680 \mathrm{~mL}$ of water to make a $0.7 \%, 1.4 \%, 2.1 \%, 2.8 \%$, and $3.5 \%$ density gradient, respectively.

The aluminum phosphate sol (Al-P) agent was prepared according to Table 1. Firstly, $\mathrm{H}_{3} \mathrm{PO}_{4}$ was added into pure water at a temperature of $90{ }^{\circ} \mathrm{C}$. Then, $\mathrm{Al}_{2}\left(\mathrm{SO}_{4}\right)_{3}$ was slowly added into the above solution while being evenly stirred until it became a transparent mixture.

Table 1. The Mass Ratio of the Al-P Sol Agent

\begin{tabular}{|c|c|c|c|}
\hline Mass Ratio & Mass of $\mathrm{H}_{3} \mathrm{PO}_{4}(\mathrm{~g})$ & Mass of $\mathrm{Al}_{2}\left(\mathrm{SO}_{4}\right)_{3}(\mathrm{~g})$ & Mass of Pure Water $(\mathrm{g})$ \\
\hline 1 to 1 & 14.2 & 14.2 & 680 \\
\hline 1 to 2 & 14.2 & 28.4 & 680 \\
\hline 1 to 4 & 14.2 & 56.8 & 680 \\
\hline 2 to 1 & 28.4 & 14.2 & 680 \\
\hline 4 to 1 & 56.8 & 14.2 & 680 \\
\hline
\end{tabular}

The alumina silica sol (Al-Si) agent was prepared according to Table 2. Firstly, the sodium silicate was diluted with $142 \mathrm{~g}$ of pure water. Secondly, $\mathrm{Al}_{2}\left(\mathrm{SO}_{4}\right)_{3}$ was added to $680 \mathrm{~g}$ of pure water. Thirdly, the diluted sodium silicate was slowly added to the $\mathrm{Al}_{2}\left(\mathrm{SO}_{4}\right)_{3}$ solution while being evenly stirred. Finally, some dilute sulphuric acid was dropped into the above solution to adjust the $\mathrm{pH}$ to approximately 10 to 11 .

Table 2. The Mass Ratio of the Al-Si Agent

\begin{tabular}{|c|c|c|c|c|}
\hline \multirow{2}{*}{$\begin{array}{l}\text { Mass } \\
\text { Ratio }\end{array}$} & \multicolumn{2}{|c|}{ Sodium Silicate Solution } & \multicolumn{2}{|c|}{$\mathrm{Al}_{2}\left(\mathrm{SO}_{4}\right)_{3}$ Solution } \\
\hline & $\begin{array}{l}\text { Mass of odium } \\
\text { silicate }(\mathrm{g})\end{array}$ & $\begin{array}{c}\text { Mass of pure } \\
\text { water }(\mathrm{g})\end{array}$ & $\begin{array}{c}\text { Mass of } \mathrm{Al}_{2}\left(\mathrm{SO}_{4}\right)_{3} \\
(\mathrm{~g})\end{array}$ & $\begin{array}{c}\text { Mass of pure } \\
\text { water }(\mathrm{g})\end{array}$ \\
\hline 1 to 1 & 14.2 & 142 & 14.2 & 680 \\
\hline 1 to 5 & 14.2 & 142 & 71 & 680 \\
\hline 1 to 10 & 14.2 & 142 & 142 & 680 \\
\hline 5 to 1 & 71 & 142 & 142 & 680 \\
\hline 10 to 1 & 142 & 142 & 14.2 & 680 \\
\hline
\end{tabular}

Anti-mildew property test

The anti-mildew performance was determined in accordance with the GB/T standard 18261 (2013). The dimension of bamboo bundles is $40 \mathrm{~mm} \times 20 \mathrm{~mm} \times 4 \mathrm{~mm}(L$ $\times W \times H$ ). The cut bamboo bundles were firstly subjected to a sterilization process and then put on the culture medium full of mildew. The environmental condition of the mildew resistance test was $28{ }^{\circ} \mathrm{C}$ and 85 to $93 \%$ of humidity for four weeks. The mildew control 
effectiveness (MCE) was used to assess the anti-mildew performance, which was calculated according to Table 3 and Eq. 1,

$$
\operatorname{MCE}=\left(1-\frac{D_{1}}{D_{0}}\right) * 100 \%,
$$

where $D_{1}$ is the average infection value (AIV) of the anti-mildew samples and $D_{0}$ is the AIV of the control samples. In addition, the average mildew control effectiveness (AMCE) of the three types of selected mildews (Aspergillus niger V. Tiegh (AVT), Penicillium citrinum Thom (PCT), and Trichoderma viride Pers. ex Fr. (TPF)) and one stain fungi (Botryodiplodia theobromae Pat. (BTP)), was calculated according to Eq. 2.

$$
A M C E=\text { Average of }\left(\mathrm{MCE}_{A V T}, \mathrm{MCE}_{P C T}, \mathrm{MCE}_{T P E} \text { and } \mathrm{MCE}_{B T P}\right)
$$

The infection value (IV) was determined by the guidelines outlined in Table 3 , and the BB anti-mildew treatment and mildew resistance test is showed in Fig. 1.

Table 3. Grading for the Degree of Infection

\begin{tabular}{|c|c|c|}
\hline IV & Area of Infection & Degree of Stain \\
\hline 0 & No hypha or mold & Normal surface and internal color \\
\hline 1 & $\begin{array}{c}\text { Surface infection area less } \\
\text { than } 1 / 4\end{array}$ & $\begin{array}{c}\text { Only few dots of stain (dot diameter less than } 2 \mathrm{~mm} \text { ); } \\
\text { normal internal color }\end{array}$ \\
\hline 2 & $\begin{array}{c}\text { Surface infection area } \\
\text { between } 1 / 4 \text { and } 1 / 2\end{array}$ & $\begin{array}{c}\text { Continual surface stain area over } 1 / 3 \text { or non-continual } \\
\text { stain area over } 1 / 2 ; \text { normal internal color }\end{array}$ \\
\hline 3 & $\begin{array}{c}\text { Surface infection area } \\
\text { between } 1 / 2 \text { and } 3 / 4\end{array}$ & $\begin{array}{c}\text { Continual surface stain area over } 1 / 3 \text { or non-continual } \\
\text { stain area over } 1 / 2 ; \text { internal stain area less than } 1 / 10\end{array}$ \\
\hline 4 & $\begin{array}{c}\text { Surface infection area over } \\
3 / 4\end{array}$ & Surface stain area over $3 / 4 ;$ internal stain area over $1 / 10$ \\
\hline
\end{tabular}

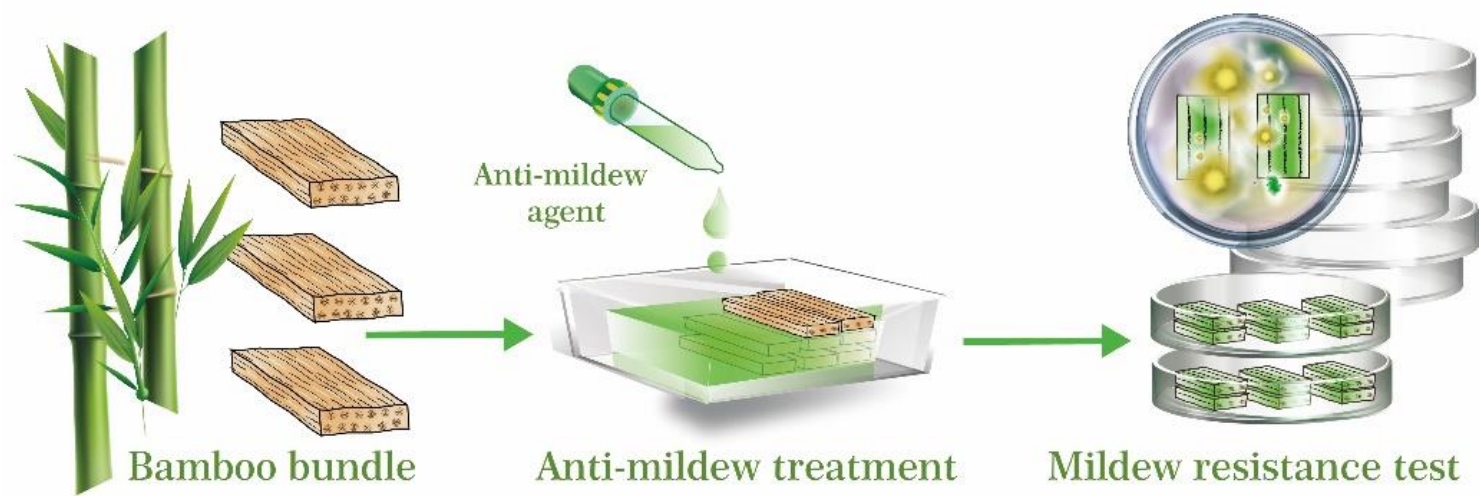

Fig. 1. BB anti-mildew treatment and mildew resistance test

Statistical analysis

One-way analysis of variance (ANOVA) was conducted with the data from the tests using Excel 2016 analysis (Microsoft Co. LTD., Redmond, WA). The results from the ANOVA were presented at the $95 \%$ confidence level. 


\section{RESULTS AND DISCUSSION}

\section{Effect of the Boric Anti-mildew Agent Treatment}

As shown in Fig. 2a, the MCE of the bamboo bundles was significantly different with the different concentrations of the boric acid solution. The stain fungi resistance was higher than the resistance to the mildew. As the concentration of the boric acid solution increased, the MCE of bamboo against AVT, TPF, and BTP also gradually increased, while the MCE against PCT was reduced. The cell structure of the fungi could be destroyed by the boron agent, leading to cellular leakage (Liu et al. 2018). The MCE of the TPF infected samples fell sharply at a $2 \%$ concentration. At the same concentration of the solution, the order of the MCE values were as follows: TPF was less than PCT, which was less than AVT, which was less than BTP. As the concentration increased, the AMCE slowly increased. When the concentration was greater than $4 \%$, the AMCE started to flatten, with a $51.0 \%, 59.8 \%$, and $62.5 \%$ improvement with a concentration of $2 \%, 4 \%$, and $10 \%$, respectively. There was an $8.83 \%$ improvement in the AMCE from $2 \%$ to $4 \%$ solution concentration, which was greater than the improvement from the $4 \%$ to $10 \%$ solution. Considering the AMCE value, the MCE of the TPF infected samples, and the costeffectiveness, a $2 \%$ concentration could be the most effective concentration. Figure $2 \mathrm{~b}$ showed the digital image of the bamboo bundles after the stain and mildew infections with a solution concentration of $2 \%$. The infection was clearly demonstrated in the AVT and BTP infected bamboo surfaces. Boric anti-mildew agent has shown high effectiveness as anti-fungal agent for bamboo bundles.

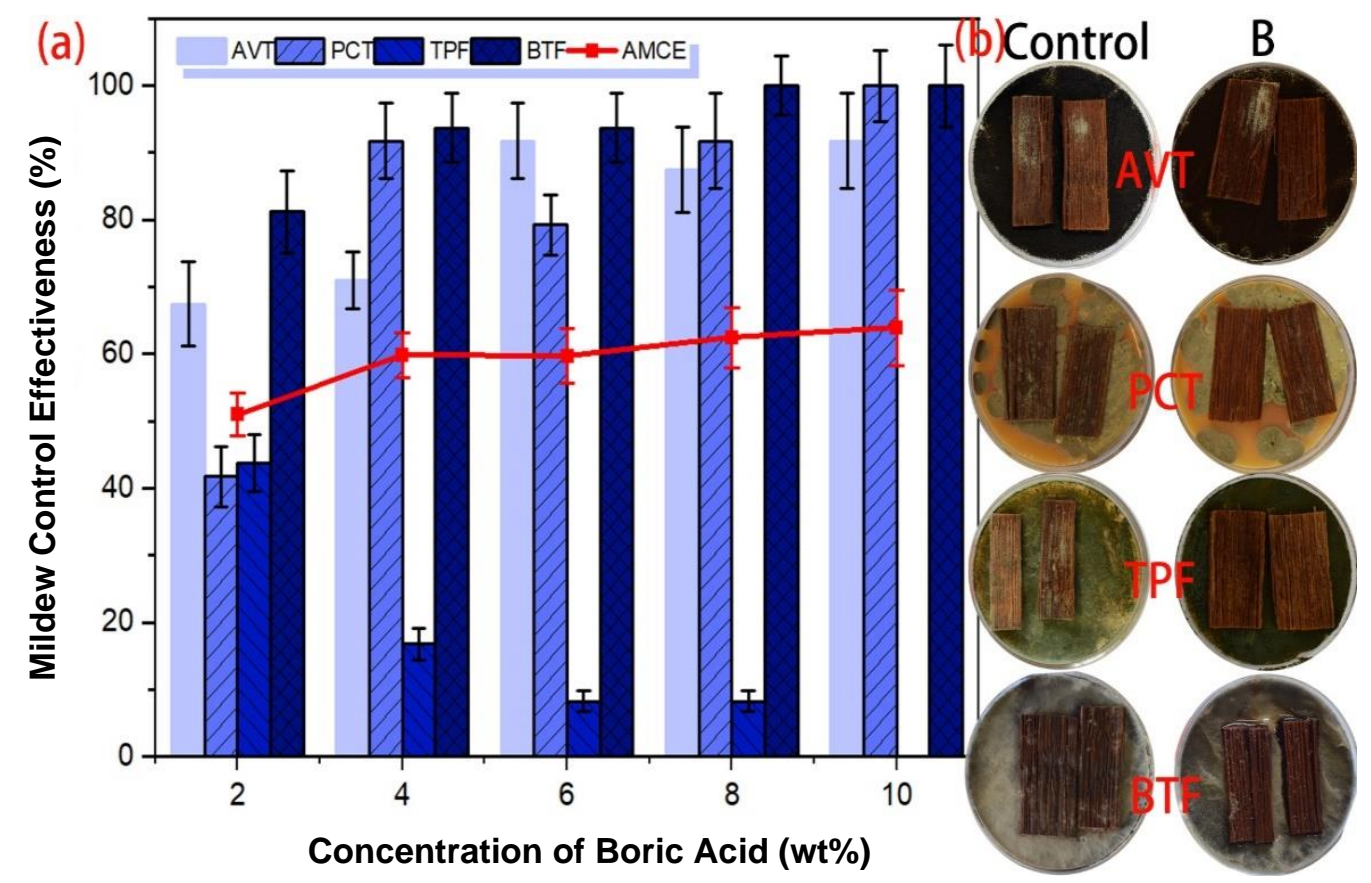

Fig. 2. The effect of the boron anti-mildew agent: (a) the MCE and AMCE results with different concentrations; and (b) digital images of the control and treated BB infected by mildew and stain fungi 


\section{Effect of the Copper Anti-mildew Agent Treatment}

As shown in Fig. 3 (a), the anti-mildew effect was better than the anti-stain fungi effect, especially the anti-AVT results. As the copper content increased, the MCE of the bamboo bundles with TPF first decreased and then increased, which showed the opposite trend of the PCT and BTP samples. At the same solution concentration, the increasing order of the MCE was as follows: BTP was less than TPF, which was less than PCT, which was less than AVT. When the concentration level was $0.7 \%$ to $1.4 \%$, the AMCE gradually increased. However, when the concentration level exceeded 1.4\%, the AMCE gradually decreased. This indicated that the addition of copper in a certain concentration range was beneficial to mold prevention. When the concentrations were $0.7 \%, 1.4 \%$, and $3.5 \%$, the AMCE was $75.00 \%, 81.92 \%$, and $69.42 \%$, respectively. When the concentration increased from $0.7 \%$ to $1.4 \%$, the AMCE increased by only $6.92 \%$. In comparison, the AMCE decreased by $12.50 \%$ when the concentration increased from $1.4 \%$ to $3.5 \%$, which indicated that the best concentration for copper anti-mold agents was $0.7 \%$. Figure $3 \mathrm{~b}$ showed the digital images of the bamboo bundles after the stain and mildew infections at a concentration of $0.7 \%$.

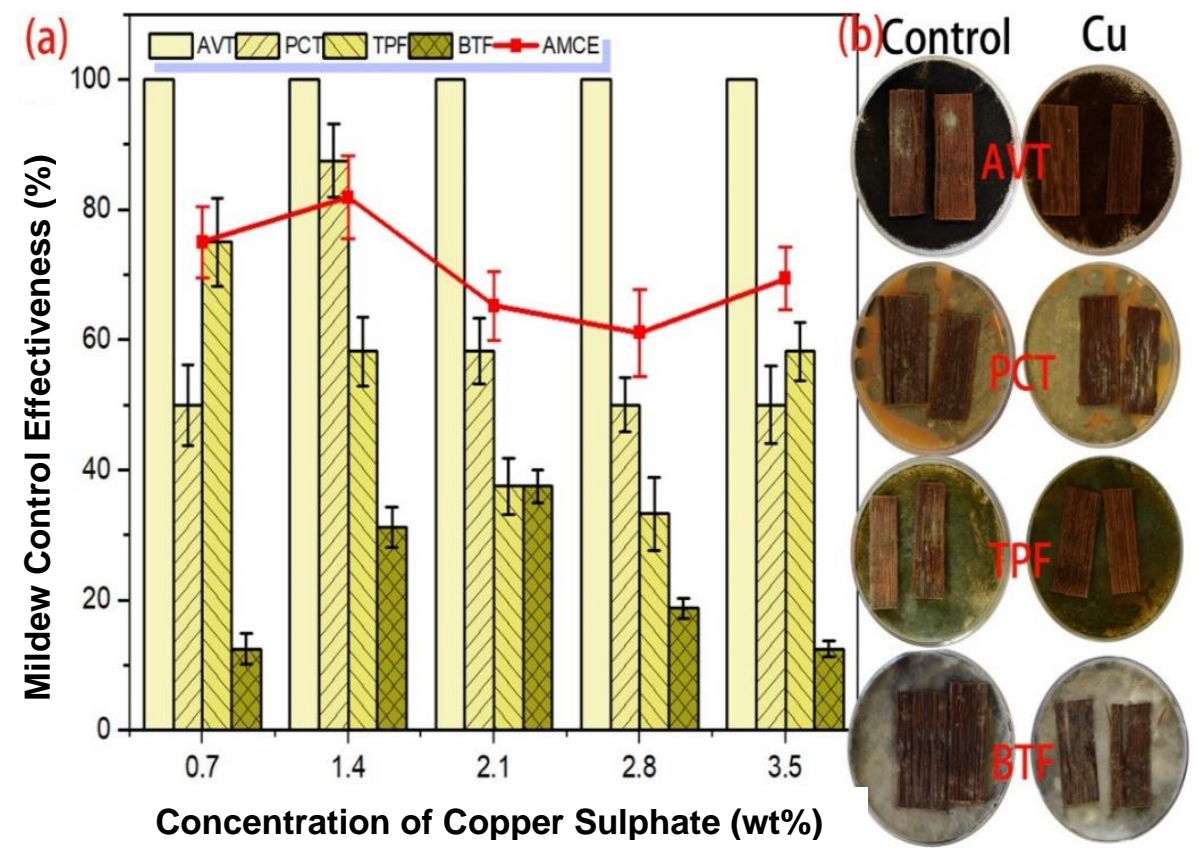

Fig. 3. The effect of the copper anti-mildew agent: (a) the MCE and AMCE results with different concentrations; and (b) digital images of the control and treated BB infected by mildew and stain fungi

\section{Effect of the Aluminum Phosphate Sol (Al-P) Anti-mildew Agent Treatment}

Figure $4 \mathrm{a}$ shows that the different mass ratios of Al-P significantly influenced the MCE, of which the effect on the AVT and PCT was pronounced. With the gradual increase in the mass ratio of Al-P, the MCE of the bamboo bundles for AVT decreased and then tended to flatten, while the MCE of TPF and PCT increased at first and gradually decreased; at the same time, the MCE of BTP steadily increased. At the same mass ratio, the order of the MCE values are as follows: AVT was less than TPF, which was less than BTP, which was less than PCT. When the mass ratio was 1 to 4 , the AMCE reached the highest value of $49.9 \%$. When the mass ratio was at 1 to 1 , the MCE of TPF and PCT 
reached the highest value of $41.8 \%$ and $91.8 \%$, respectively, while the AMCE also reached $45.9 \%$, which was only $4 \%$ lower than the highest value. In addition, the MCE of BTP was $47.75 \%$. Therefore, taking into account the cost-effectiveness of the anti-mold agent and the MCE, the most suitable mass ratio of Al-P was 1 to 1 , which was the addition of $2 \%$ phosphorus. Figure $4 \mathrm{~b}$ shows the digital images of the bamboo bundles after the stain and mildew infections with Al-P at a mass ratio of 1 to 1 . The Al-P sol could build a threedimension structure on the surface of bamboo bundles (Chen et al. 2018). They form a protective film over its surface to strengthen the natural defense mechanism against damage from mildew.

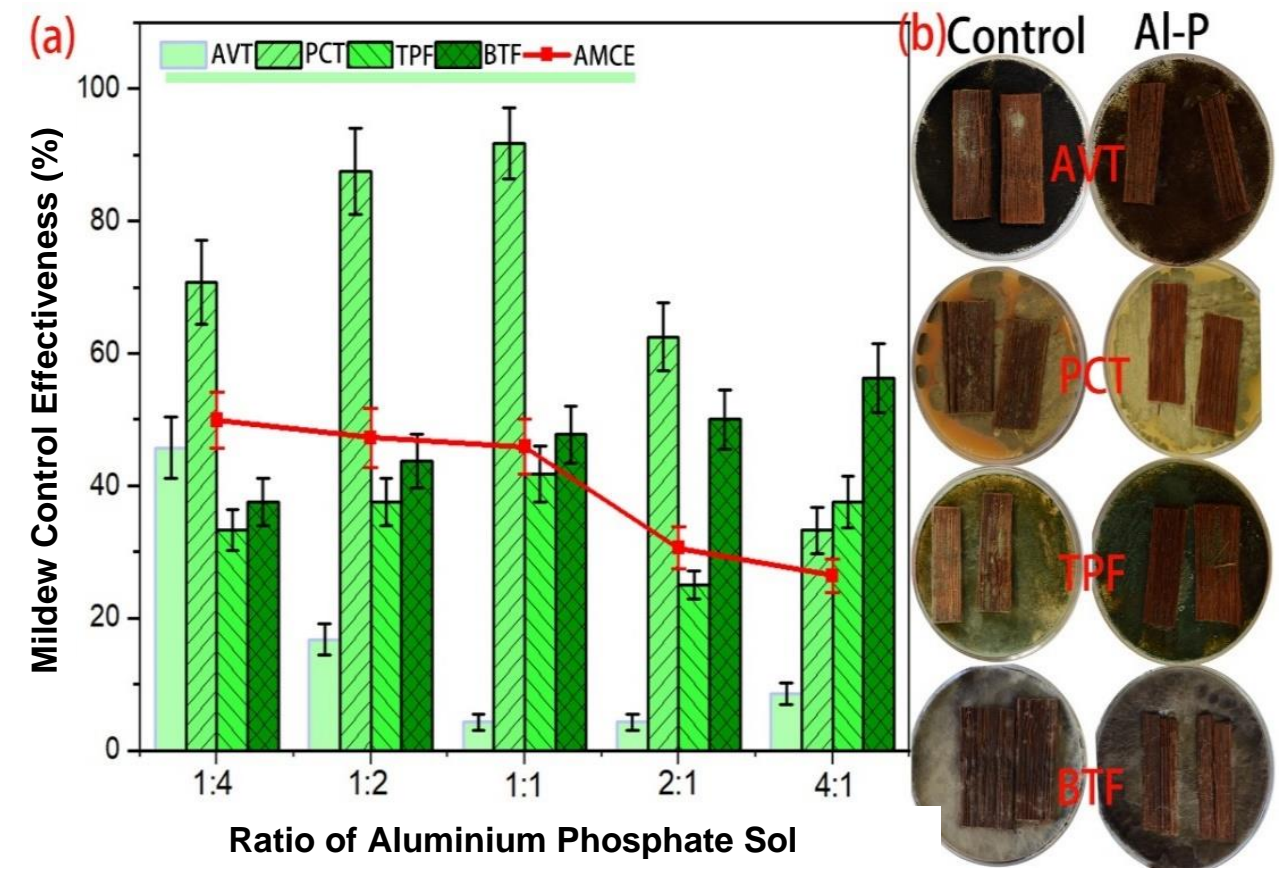

Fig. 4. The effect of the Al-P anti-mildew agent: (a) the MCE and AMCE results with different concentrations; and (b) digital images of the control and treated BB infected by mildew and stain fungi

\section{Effect of the Aluminum Silicon Sol (AI-Si) Anti-mildew Agent Treatment}

Figure 5a shows that the different mass ratios of sodium silicate and aluminum salt had significantly different MCE values, especially for TPF. With the gradual increase of the mass ratio, the MCE of the bamboo bundles for AVT and PCT first decreased and then increased, while the MCE of TPF and BTP showed a gradual increase as the overall trend. At the same mass ratio, the MCE increasing trend was as follows: AVT was less than PCT, which was less than BTP, which was less than TPF. An AMCE of 13.92\% was obtained when the mass ratio was 1 to 1 . When the mass ratio was 10 to 1 , the AMCE reached the highest value of $59.8 \%$, which was an increase of $45.8 \%$. This indicated that the increase in the $\mathrm{Al}$ to $\mathrm{Si}$ mass ratio was beneficial to the resistance of mold and stain fungus by the bamboo bundles. Therefore, the proper mass ratio of $\mathrm{Al}$ to $\mathrm{Si}$ was 10 to 1; Fig. 5b shows the digital images of the bamboo bundles treated at this mass ratio. The $\mathrm{Si}-\mathrm{Al}$ mesopore structure covered on the surface of bamboo fiber can effectively act as physical barriers and help to improve the anti-mildew property and leachability property (Wu et al. 2019). 


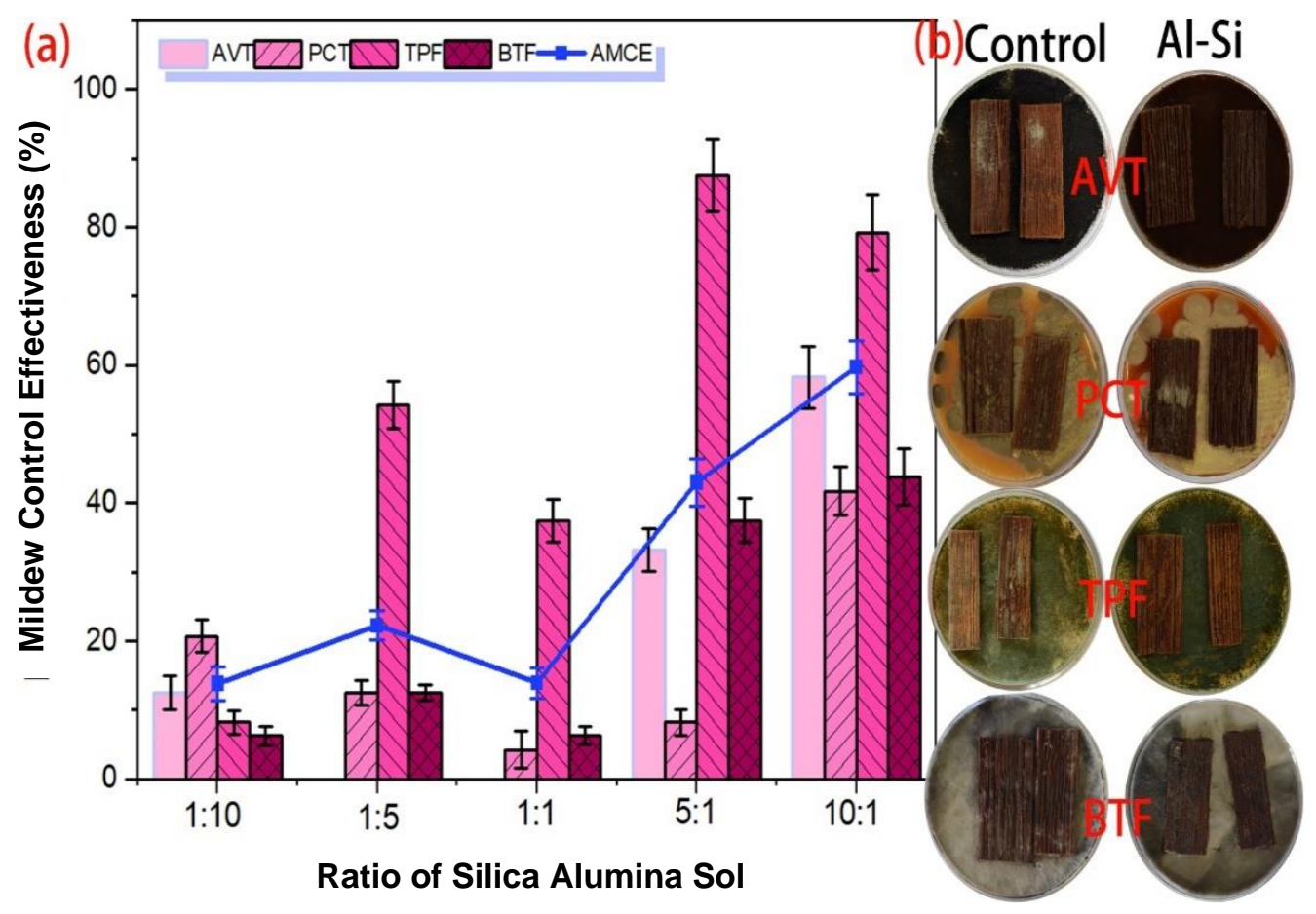

Fig. 5. The effect of the AI-Si anti-mildew agent: (a) the MCE and AMCE results with different concentrations; and (b) digital images of the control and treated BB infected by mildew and stain fungi
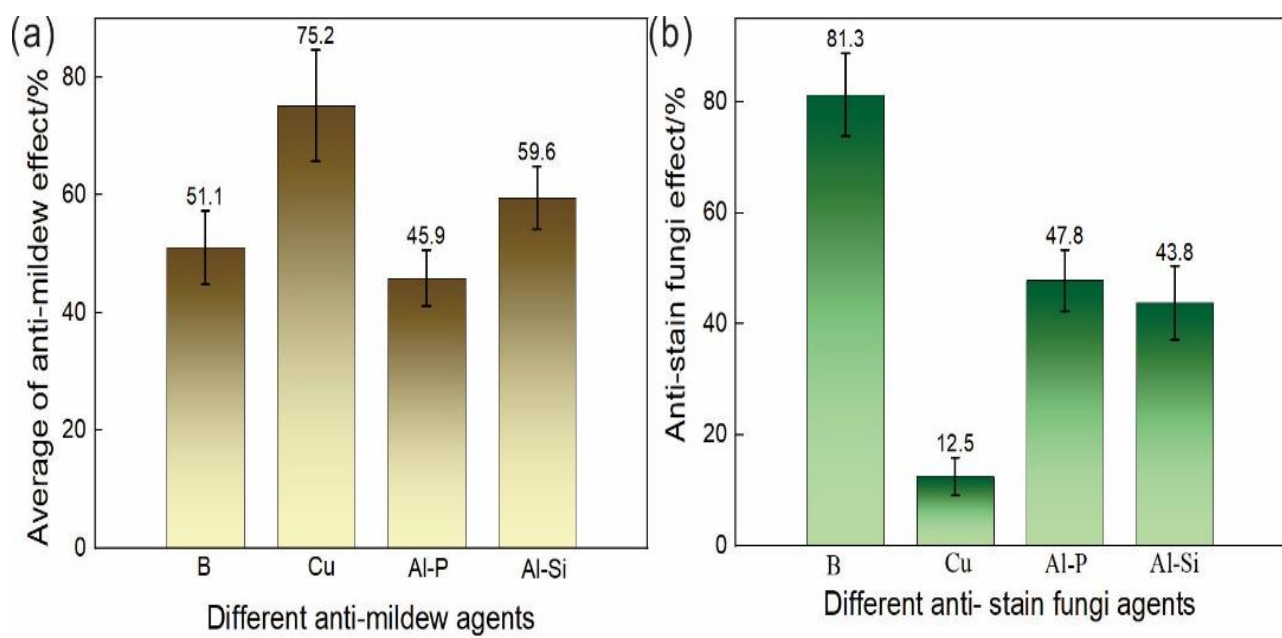

Fig. 6. The performance of the different anti-mold agents

\section{Comparison of Selected Anti-mildew and Anti-stain Fungi Agents}

As shown in Fig. 6, there were considerable differences between the average of the anti-mildew (AVT, PCT, and TPF) and anti-stain fungus (BTP) effects at their respective optimal concentration or mass ratio for $\mathrm{B}, \mathrm{Cu}, \mathrm{Al}-\mathrm{P}$, and $\mathrm{Al}-\mathrm{Si}$. The decreasing order of the anti-mildew properties was as follows: $\mathrm{Cu}>\mathrm{Al}-\mathrm{Si}>\mathrm{B}>\mathrm{Al}-\mathrm{P}$ (as shown in Fig. 6a). The sensitivity of the different anti-mildew agents and anti-stain fungus were also different. The order of the resistance of stain fungi was as follows: B was greater than Al-P, which was greater than $\mathrm{Al}-\mathrm{Si}$, which was greater than $\mathrm{Cu}$ (as shown in Fig. 6b). The boron agent 
was more suitable for anti-stain fungus, while the copper agent was better for anti-mildew. In addition, the Al-P and Al-Si agents showed great suitability as both an anti-mildew and anti-stain fungus agent.

\section{CONCLUSIONS}

1. The optimal concentrations of the boron and copper anti-mold agents were $2 \%$ and $0.7 \%$, respectively. The optimal mass ratios of aluminum phosphate sol and silicone aluminum sol were 1 to 1 ( $2 \%$ phosphoric acid addition) and 10 to 1 (aluminum salt addition was $1.5 \%$ ), respectively.

2. The effectiveness of each anti-mildew agent to different molds varied. Precisely, the effect of the B agent on Botryodiplodia theobromae Pat. (BTP) and Aspergillus niger $\mathrm{V}$. Tiegh (AVT) was more obvious. In addition, the $\mathrm{Cu}$ agent was more effective for combating AVT and PCT. Furthermore, the aluminum phosphate sol had a better effect on both PCT and BTP.

3. The Al-Si agent proved more effective for hindering the growth of both TPF and BTP. There were significant differences in the prevention and treatment effect of the different mold inhibitors on mold and discoloration bacteria.

4. The order of effectiveness of the anti-mold properties is as follows: $\mathrm{Cu}>\mathrm{Al}-\mathrm{Si}>\mathrm{B}>$ Al-P. In addition, the anti-color resistance order is as follows: $\mathrm{B}>\mathrm{Al}-\mathrm{P}>\mathrm{Al}-\mathrm{Si}>\mathrm{Cu}$.

\section{ACKNOWLEDGEMENTS}

This work was financed by the Scientific Research Foundation of Wuyi University (Grant No. YJ201913), the Fujian Educational and Scientific Research Projects for Young and Middle-aged Teachers (Grant No. JAT190785), and the Fujian Natural Science Foundation (Youth Innovation) (Grant No.2020J05219).

\section{ABBREVIATIONS}

Boric acid (B); copper (Cu); alumina phosphate sol (Al-P); alumina silicate sol (Al$\mathrm{Si}$ ); the mildew control effectiveness (MCE); Aspergillus niger V. Tiegh (AVT); Penicillium citrinum Thom (PCT); Trichoderma viride Pers. ex Fr. (TPF); Botryodiplodia theobromae Pat. (BTP); the average MCE of the three types strains of mildew (AVT, PCT, and TPF) and one type of stain fungi (BTP) (AMCE); bamboo bundles (BB); infection value (IV); average IV (AIV); one-way analysis of variance (ANOVA). 


\section{REFERENCES CITED}

Chen, F., Yang, X., and Wu, Q. (2009). "Antifungal capability of $\mathrm{TiO}_{2}$ coated film on moist wood," Building and Environment 44(5), 1088-1093. DOI: 10.1016/j.buildenv.2008.07.018

Chen, T., Wu, Z., Wang, X. A., Wang, W., Huang, D., Wei, Q., Wu, B., and Xie, Y. (2018). Hierarchical lamellar aluminophosphate materials with porosity as ecofriendly inorganic adhesive for wood-based boards. ACS Sustainable Chemistry \& Engineering, 6(5), 6273-6280. DOI: 10.1021/acssuschemeng.8b00078

Chen, H., Wu, J., Shi, J., Zhang, W., and Wang, G. (2021). "Strong and highly flexible slivers prepared from natural bamboo culm using $\mathrm{NaOH}$ pretreatment," Industrial Crops and Products 170, 1-10. DOI: 10.1016/j.indcrop.2021.113773

Cheng, D. L., Jiang, S. X., and Zhang, Q. S. (2013). "Mould resistance of moso bamboo treated by two step heat treatment with different aqueous solutions," European Journal of Wood and Wood Products 71(1), 143-145. DOI: 10.1007/s00107-0120654-3

Cull, M. R., Dobbs, A. J., and Williams, N. (1983). "Polychlorodibenzo-p-dioxins (PCDDs) in commercial pentachlorophenol (PCP) used in wood preservation," Chemosphere 12(4), 483-485. DOI: 10.1016/0045-6535(83)90197-2

Filpo, G. D., Palermo, A. M., Rachiele, F., and Nicoletta, F. P. (2013). "Preventing fungal growth in wood by titanium dioxide nanoparticles," International Biodeterioration \& Biodegradation 85, 217-222. DOI: 10.1016/j.ibiod.2013.07.007

GB/T 18261 (2013). "Test method for anti-mildew agents in controlling wood mould and stain fungi," Standardization Administration of China, Beijing, China.

Guo, A., Cooper, P. A., and Ung, T. (2005). "Fixation and leaching characteristics of acid copper chromate (ACC) compared to other chromium-based wood preservatives," Forest Products Journal 55(7-8), 72-75.

Jalali, S. A. H., Allafchian, A. R., Banifatemi, S. S., and Tamai, I. A. (2016). "The antibacterial properties of $\mathrm{Ag} / \mathrm{TiO}_{2}$ nanoparticles embedded in silane sol-gel matrix," Journal of the Taiwan Institute of Chemical Engineers 66, 357-362. DOI: 10.1016/j.jtice.2016.06.011

Ju, Z., Zhan, T., Cui, J., Brosse, N., Zhang, H., Hong, L., and Lu, X. (2021). “Ecofriendly method to improve the durability of different bamboo (Phyllostachys pubescens, Moso) sections by silver electrochemical treatment," Industrial Crops and Products 172, 1-13. DOI: 10.1016/j.indcrop.2021.113994

Kang, F., Cheng, Y., Huang, Q., Wei, Y., Zhang, R., and Yang, F. (2009). “Application status of microwave technology in the quarantine and treatment of pests in my country," Plant Protection 35(6), 36-39. DOI: 10.3969/j.issn.0529-1542.2009.06.007

Kitchin, K. T., and Brown, J. L. (1986). "1,2-Dibromoethane causes rat hepatic DNA damage at low doses," Biochemical and Biophysical Research Communications 141(2), 723-727. DOI: 10.1016/S0006-291X(86)80232-7

Kjellow, A. W., Henriksen, O., Sørensen, J. C., Johannsen, M., and Felby, C. (2010). "Partitioning of organic biocides between wood and supercritical carbon dioxide," The Journal of Supercritical Fluids 52(1), 1-5. DOI: 10.1016/j.supflu.2009.12.005

Lam, M., Migonney, V., and Falentin-Daudre, C. (2021). "Review of silicone surface modification techniques and coatings for antibacterial/antimicrobial applications to improve breast implant surfaces," Acta Biomaterialia 121, 68-88. DOI:

10.1016/j.actbio.2020.11.020 
Li, J., Ren, D., Wu, Z., Huang, C., Yang, H., Chen, Y., and Yu, H. (2017a). "Visible-lightmediated antifungal bamboo based on $\mathrm{Fe}$-doped $\mathrm{TiO}_{2}$ thin films," RSC Advances 7(87), 55131-55140. DOI: 10.1039/C7RA10103A

Li, J., Wu, Z., Bao, Y., Chen, Y., Huang, C., Li, N., He, S., and Chen, Z. (2017b). "Wet chemical synthesis of $\mathrm{ZnO}$ nanocoating on the surface of bamboo timber with improved mould-resistance," Journal of Saudi Chemical Society 21(8), 920-928. DOI: $10.1016 /$ j.jscs.2015.12.008

Li, Y., and Feng, P. (2019). "Bamboo resources in China based on the ninth national forest inventory data," World Bamboo and Rattan 17(6), 45-48. DOI: 10.12168/sjzttx.2019.06.010

Lian, C., and Wu, Z. (2021). "Research progress on environmental characteristics of bamboo materials and its products," Journal of Forestry Engineering 6, 1-8. DOI: 10.13360/j.issn.2096-1359.202101016

Liu, Q., Li, J., Zhong, X., Dai, Z., Lu, Z., Yang, H., and Chen, R. (2018). “Enhanced antibacterial activity and mechanism studies of $\mathrm{Ag} / \mathrm{Bi}_{2} \mathrm{O}_{3}$ nanocomposites," Advanced Powder Technology 29(9), 2082-2090. DOI: 10.1016/j.apt.2018.05.015

Mercer, T. G., and Frostick, L. E. (2014). "Evaluating the potential for environmental pollution from chromated copper arsenate (CCA)-treated wood waste: A new mass balance approach," Journal of Hazardous Materials 276, 10-18. DOI: 10.1016/j.jhazmat.2014.05.006

Okyay, T. O., Bala, R. K., Nguyen, H. N., Atalay, R., Bayam, Y., and Rodrigues, D. F. (2015). "Antibacterial properties and mechanisms of toxicity of sonochemically grown ZnO nanorods," RSC Advances 5(4), 2568-2575. DOI: 10.1039/C4RA12539H

Petkova, P., Francesko, A., Fernandes, M. M., Mendoza, E., Perelshtein, I., Gedanken, A., and Tzanov, T. (2014). "Sonochemical coating of textiles with hybrid $\mathrm{ZnO} /$ chitosan antimicrobial nanoparticles," ACS Applied Materials \& Interfaces 6(2), 1164-1172. DOI: $10.1021 / \mathrm{am} 404852 \mathrm{~d}$

Pries, M., and Mai, C. (2013). "Fire resistance of wood treated with a cationic silica sol. European Journal of Wood and Wood Products 71(2), 237-244. DOI: 10.1007/s00107-013-0674-7

Saka, S., Miyafuji, H., and Tanno, F. (2001). "Wood-inorganic composites prepared by the sol-gel process," Journal of Sol-Gel Science and Technology 20(2), 213-217. DOI: $10.1023 / \mathrm{A}: 1017330925894$

Singh, L., Sridharan, S., Thul, S. T., Kokate, P., Kumar, P., Kumar, S., and Kumar, R. (2020). "Eco-rejuvenation of degraded land by microbe assisted bamboo plantation," Industrial Crops and Products 155, 1-10. DOI: 10.1016/j.indcrop.2020.112795

Stirling, R., Drummond, J., Zhang, J., and Ziobro, R. J. (2008). "Micro-distribution of micronized copper in southern pine," in: Proceedings of the $39^{\text {th }}$ Annual Meeting of International Research Group on Wood Preservation, 25-29 May, Istanbul, Turkey, pp. 1-16.

Sun, F., Bao, B., Ma, L., Chen, A., and Duan, X. (2012). "Mould-resistance of bamboo treated with the compound of chitosan-copper complex and organic fungicides," Journal of Wood Science 58(1), 51-56. DOI: 10.1007/s10086-011-1223-9

Sun, F., Jiang, Z., Fei, B., Yu, Z., and Wang, H. (2011). "Effect of $\gamma$-ray application on bamboo mold resistance," China Wood Industry 25(3), 23-25. DOI: 10.19455/j.mcgy.2011.03.007

Wu, Z., Huang, D., Wei, W., Wang, W., Wang, X., Wei, Q., Niu, M., Lin, M., Rao, J., and Xie, Y. (2019). "Mesoporous aluminosilicate improves mildew resistance of bamboo 
scrimber with Cu-B-P anti-mildew agents," Journal of Cleaner Production 209, 273 282. DOI: $10.1016 /$ j.jclepro.2018.10.168

Zhang, H., Li, H., Li, Y., Xiong, Z., Zhang, N., Lorenzo, R., and Ashraf, M. (2021). "Effect of nodes on mechanical properties and microstructure of laminated bamboo lumber units," Construction and Building Materials 304, 1-14. DOI: 10.1016/j.conbuildmat.2021.124427

Zhang, R., Li, Y., He, Y., and Qin, D. (2020). "Preparation of iodopropynyl butycarbamate loaded halloysite and its anti-mildew activity," Journal of Materials Research and Technology 9(5), 10148-10156. DOI: 10.1016/j.jmrt.2020.07.019

Zhang, G., Liu, Y., Morikawa, H., and Chen, Y. (2013). “Application of ZnO nanoparticles to enhance the antimicrobial activity and ultraviolet protective property of bamboo pulp fabric," Cellulose 20(4), 1877-1884. DOI: 10.1007/s10570-0139979-2

Zhu, J., Wang, H., Guo, F., Salmén, L., and Yu, Y. (2021). "Cell wall polymer distribution in bamboo visualized with in situ imaging FTIR," Carbohydrate Polymers 274, 1-9. DOI: $10.1016 /$ j.carbpol.2021.118653

Article submitted: September 28, 2021; Peer review completed: November 9, 2021; Revised version received and accepted: November 11, 2021; Published: November 15, 2021.

DOI: 10.15376/biores.17.1.243-254 